\title{
ANGIOGENESIS AND CK19 EXPRESSION IN PAPILLARY THYROID CARCINOMA
}

\author{
D. Malinova*, M. Tzaneva \\ Department of General and Clinical Pathology, Forensic Sience and Deontology, Medical University, \\ Varna, Bulgaria
}

\begin{abstract}
Purpose: Aim of the present study is to evaluate immunohistochemically the diagnostic value of CK19 in papillary thyroid carcinoma (PC) and to determine the microvascular density (MDV) in tumor tissue by CD34.

Methods: We studied immunohistochemical expression of CK19 in both tumor tissue and adjacent non-tumor tissue of ten patients that had undergone surgical resection for PC. We evaluated the MVD by CD34, an endothelial marker, in the same zones.

Results: All neoplasms were CK19 positive and the tumor tissue showed a diffuse and strong cytoplasmic expression. In most of the cases, the adjacent non-tumor tissue was negative for CK19. However, a focal modarate staining occured in oncocytic cells and in areas of degeneration. The MVD in tumor tissue was $29.1 \pm 6.05$. The microvessels were unevenly distributed as opposed to those in the adjacent tissue. The MVD in non-tumor tissue was $36.4 \pm 6.38$.

Conclusions: CK19 is a highly specific marker for PC, which means that it may be used as an additive tool in diagnosis of this carcinoma.. Angiogenesis is reduced and this may affect the biological behavior of the PC.
\end{abstract}

Key words: papillary carcinoma, microvessel density, CD 34, CK 19.

\section{INTRODUCTION}

Accounting approximately $75-85 \%$ of all malignant thyroid neoplasms, papillary carcinoma (PC) is the most common type of thyroid cancer (1). It originates from the thyroid follicular epithelium. In recent years was established, that PC is associated with genetic alterations, growth factors, and physical factors, such as radiation. Currently, studies are designed to determine which factors have important diagnostic and prognostic significance in thyroid tumors (2-6). CK19 is a low molecular weight cytokeratin, and there have been several reports on its role in the diagnosis and differential diagnosis of thyroid benign and malignant lesions, but the data are contradictory $(5,6,7)$.

It is known that the neoangiogenesis is integral part of the solid tumors and the microvascular density in a tumor correlates well with its growth and its capacity to metastasize (8). CD34 antibody is an specific endothelial

\footnotetext{
* Correspondence to: $D$. Malinova, Department of General and Clinical Pathology, Forensic Sience and Deontology, Medical University - Varna, Bulgaria, phone: 052/978 389, e-mail: dmalinova@gmail.com
}

marker for detection of all mature and immature vascular endothelial cell (7).

Aim of the present study is to evaluate immunohistochemically the diagnostic value of CK19 in papillary carcinoma and to determine the microvascular density (MDV) in tumor tissue by CD34.

\section{MATERIAL AND METHODS}

Ten women patients with PC, collected randomly, were investigated. The age varied from 25 to 79 years (mean 48.9 years). All patients have undergone surgical resection in St.Marina University Hospital, Varna.

Paraffin-embedded specimens of formalin fixed tissue were available for each case. The sections were cut at $5 \mu \mathrm{m}$ from representative blocks, which included both tumor tissue and adjacent non-tumor tissue of each case and stained by hematoxylin and eosin. A histopathological diagnosis of the papillary carcinoma was made in accordance to WHO. Paraffin section ( $5 \mu \mathrm{m}$ thick) was processed by peroxidase-antiperoxidase technique. The used antibodies were monoclonal mouse anti-human CD34 class II clone QBEnd (Dako) and monoclonal mouse anti-human CK19 clone RCK108 (Dako). 
CK19 positive status was graded as follows: $1+$ (weak, focal staining), $2+$ (moderate focal staining), $3+$ (diffuse and strong).

Using light microscopy, we counted the number of microvessels per 400x in the area of most dense vascularization according to the method described by Saad et al. (9). Three areas were evaluated from each patient. MDV was determined as median number of all measuring. The data are presented as the mean and standard deviation. Statistical comparisons were made using analysis of variance and Student's t-test. $\quad \mathrm{P}<0.05$ was considered statistically significant.

\section{RESULTS}

Histology

All tumors showed classical features of papillary carcinoma. Papillary structures were present. A set of distinctive nuclear features, in particular: optically clear appearance, overlapping, pseudoinclusions and nuclear grooves, were found (Figure. 1). The most of the cases showed a desmoplastic stroma. In eight out of ten cases Hashimoto thyroiditis was found.

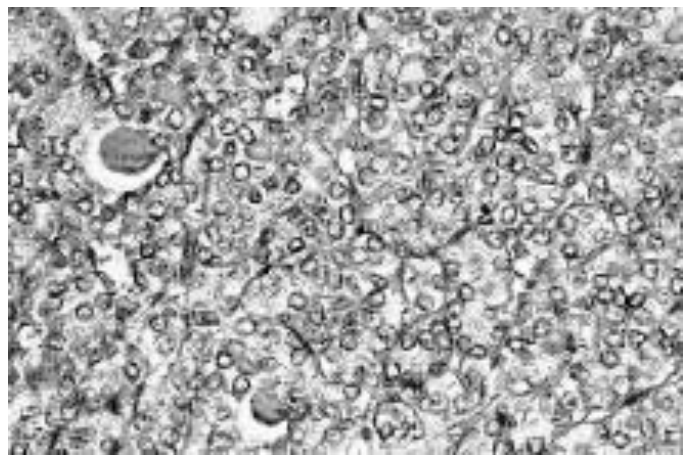

Figure 1. Tumour tissue of a papillary carcinoma with typical kind of nuclei. HE x100.

\section{Immunohistochemistry}

All 10 PC had diffuse and strong cytoplasmic CK19 expression (Figure 2). Despite focal moderate staining found in oncocytic cells and in areas of degeneration, mostly the majority of the adjacent non-tumor tissue was negative for CK19 (Figure 3).

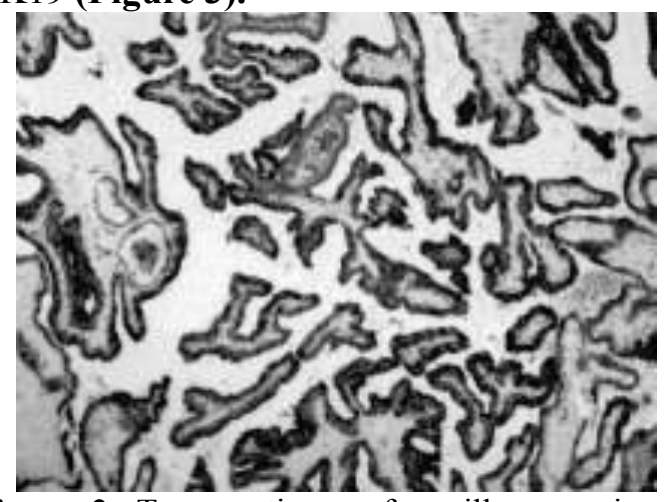

Figure 2. Tumour tissue of papillary carcinoma with diffuse and strong CK 19 expression. Immunohistochemistry x 100 .

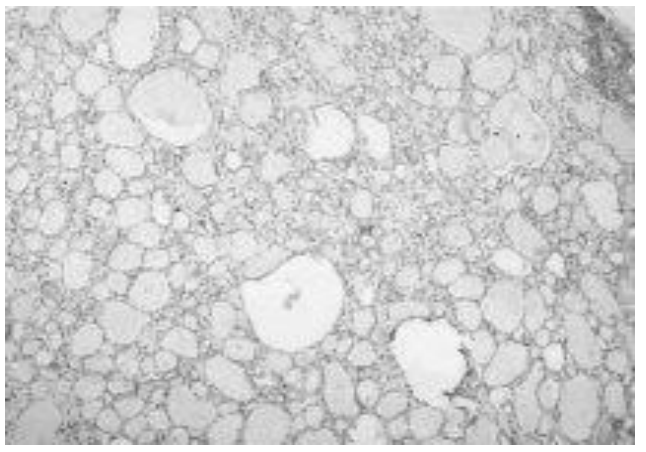

Figure 3. Non-tumour tissue is negative for CK 19. Immunohistochemistry x 100.

MVD in tumor tissue was $29.1 \pm 6.05$. They were unevenly distributed (Figure 4). In neoplastic stroma usually no larger caliber vessels were discovered, but such vessels were found in nontumor tissue. In adjacent non-tumor tissue MDV was $36.4 \pm 6.38$. Microvessels were evenly distributed (Figure 5). The blood vessels with larger caliber were found in non-tumor tissue more often of the border with the tumor (Figure 6).

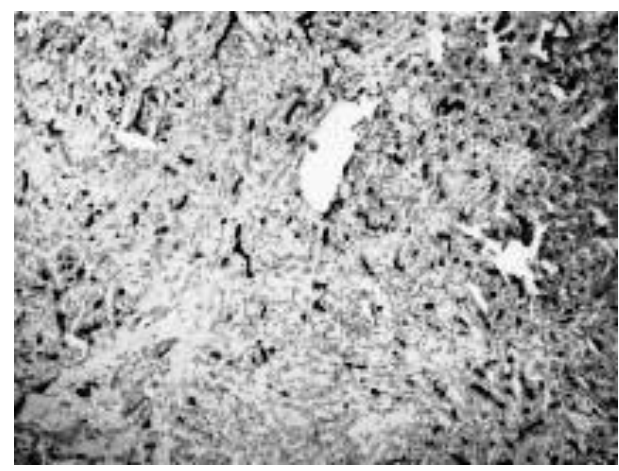

Figure 4. Tumour tissue of a papillary carcinoma with CD 34 expression. Immunohistochemistry $\mathrm{x}$ 100 .

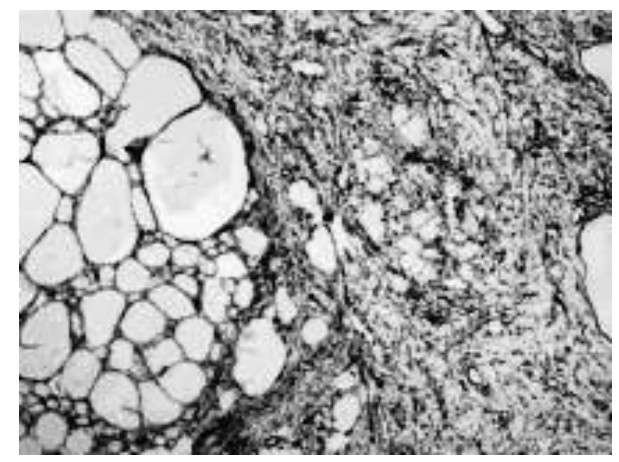

Figure 5. Non-tumour tissue with CD 34 expression. Immunohistochemistry x 100 .

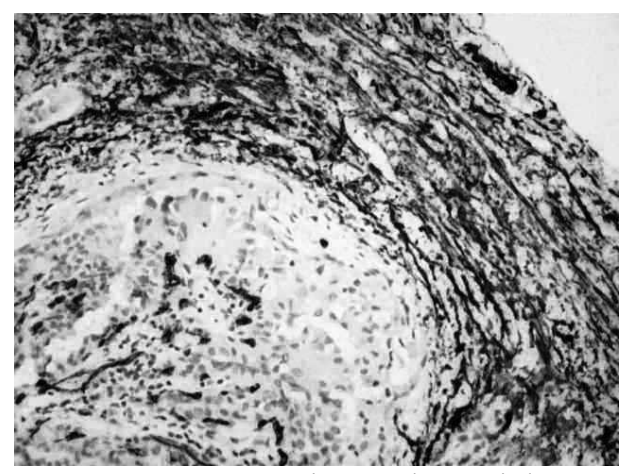

Figure 6. CD 34 expression at the periphery of the tumor. Immunohistochemistry x 100. 


\section{DISCUSSION}

In this study we found a diffuse and strong cytoplasmic CK19 expression in all PC. We established also focal and moderate staining in non-tumor tissue. These findings taken together suggest that CK19 has a diagnostic value in PC solely in diffuse and strong expression. CK19 is a member of the family cytokeratins, which participate in the integrity and cytoskeleton of the cells (10). CK19 has the lowest molecular weight of all the cytokeratins. It is normally expressed in ductal epithelium (bile ducts, pancreas, and renal collecting tubules) and in the mucosa of the gastrointestinal tract. The precise role of CK19 in tumor thyroid tissue is not yet known. According Gong et al. (11) CK19 expression in tumor tissue of papillary carcinoma is not a predictor of lymph node metastases. Also, there were no significant differences serum CK19 level between benign tumours and PC (10).

We have found a reduction in MVD in tumor tissue compared to the adjacent non-tumor tissue. Our results correspond to data of other authors which establish similar changes (12).

In addition to the reduced MVD in papillary carcinoma De la Torre et al. (12) also establish decreased MVD in proliferative lesions and benign tumors, compared with normal tissue. In this study we prefer CD34 antibody for an assessment of MVD because it is a sensitive and specific marker for use on paraffin sections. CD34 expression was found mainly in microvessels. Blood vessels with larger caliber were found in non-tumor tissue more often at the border of the tumor. Scarpino et al. (12) also describe two types of vessels in papillary thyroid carcinomas: a delicate capillary network, located in the stroma of tumour papillae and large venous spaces, located in the peritumoral fibrous tissue.

It is known that in physiological and pathological conditions angiogenesis is associated with many growth factors and their receptors. In tumor tissue of papillary carcinoma a significantly high expression of three angiogenetic factors: vascular endothelial growth factor A (VEGF-A) angiopoietin 1 (Ang1) and Angiopoietin 2 (Ang2) and their receptor Tie-2 receptor is found $(11,12,14)$. VEGF-A is a member of the family vascular endothelial growth factors, which act through cognate receptor kinases in endothelial cells to stimulate blood-vessel formation. VEGF-A has important roles in mammalian vascular development and in diseases involving abnormal growth of blood vessels (15).
Angiopoietins (Ang1 and Ang2) are structurally related growth factors, which contributed to angiogenesis upon binding to Tie2 receptor. Ang1 is known as a Tie2 agonist capable of inducing endothelial cell migration and proliferation (14). It is possible that when dedifferentiation occurs, thyroid tissue loses the ability to maintain the rich vascularization of the normal gland and show lower MDV in papillary carcinoma.

For the first time in 1955 Dailey et al. demonstrate an association between papillary thyroid cancer and Hashimoto thyroiditis (16). Literature data shows that papillary thyroid carcinoma and Hashimoto's thyroiditis occur simultaneously with a frequency varying between 0.5 and $30 \%$ (16). In this study, eight out of ten patients had a Hashimoto thyroiditis. Sheils et al. detected RET/PTC1 mutation in about $95 \%$ of investigated patients with Hashimoto thyroiditis (18). Authors suggest that the presence of mutations involving the RET/PTC oncogenes may be an early molecular indicator of papillary thyroid microcarcinoma lesions. Recent experience with the use of PCR in cytological diagnostic management of material obtained by FNAB may be of importance in detecting neoplastic lesions before they become clinically manifested (19).

In conclusion, Hashimoto thyroiditis show a high association with PC. CK19 has diagnostic value in thyroid PC solely in diffuse and intensive cytoplasmic expression in the tumor tissue. The precise mechanisms of reduced microvascular density need to be explored in the future.

\section{REFERENCES}

1. Erdem, H. Gündogdu, C. Sipal, S., Correlation of E-cadherin, VEGF, COX-2 expression to prognostic parameters in papillary thyroid carcinoma. Exp Mol Pathol, 3:12-17, 2011.

2. Ito, Y. Miyauchi, A. Kakudo, K, Hirokawa, M. Kobayashi, K. Miya, A., Prognostic significance of ki-67 labeling index in papillary thyroid carcinoma. World J Surg 34:3015-3021, 2010.

3. Barut, F. Onak Kandemir, N. Bektas, S. Bahadir, B. Keser, S. Ozdamar, SO., Universal markers of thyroid malignancies: galectin-3, HBME-1, and cytokeratin-19. Endocr Pathol 21:80-89, 2010.

4. Chiu, CG. Strugnell, SS. Griffith, OL. Jones, SJ. Gown, AM. Walker, B. Nabi, IR. Wiseman SM., Diagnostic utility of galectin-3 in thyroid cancer. Am J Pathol, 176:2067-2081, 2010. 
5. Demellawy, DEl. Nasr, A. Alowami, S., Application of CD56, P63 and CK19 immunohistochemistry in the diagnosis of papillary carcinoma of the thyroid. Diagnostic Pathology, 3:5, 2008.

6. Prasad, ML. Pellegata, NS. Huang, Y. Nagaraja, HN. Chapelle, A. Kloos, RT., Galectin-3, fibronectin-1, CITED-1, HBME1 and cytokeratin-19 immunohistochemistry is useful for the differential diagnosis of thyroid tumors. Mod Pathol, 18;48-57.2005.

7. Sahoo, S. Hoda, SA. Rosai, J. DeLellis, RA., Cytokeratin 19 immunoreactivity in the diagnosis of papillary thyroid carcinoma: a note of caution. Am J Clin Pathol, 116:696-702, 2001.

8. Weidner, N., Tumor angiogenesis: review of current applications in tumor prognostication. - Seminars Diagnostic Pat, 10:302-313. 1993.

9. Saad RS, Kordunsky L, Denning KL, et al. Lymphatic microvessel density as prognostic marker in colorectal carcinoma. Mod Pathol. 2006;19:1317-1323

10.Makki, FM. Taylor, SM. Shahnavaz, A. Andrew Leslie, A. Gallant J, Douglas, S. Teh, E. Trites, J. Bullock, M. Inglis, K, Pinto, DM. Hart, RD., Expressions of D240, CK19, galectin-3, VEGF and EGFR in papillary thyroid carcinoma $J$ Otolaryngol Head Neck Surg, 42:16.1. 2013.

11.Gong, L. Chen, P. Liu, X. Han, Y. Zhou, Y. Zhang, W. Li, H. Li, C. Xie, J., Expressions of D2-40, CK19, galectin-3, VEGF and EGFR in papillary thyroid carcinoma. Gland Surg 1:25-32, 2012.

12.De la Torre, NG. Buley, I. Wass, A. Turner, HE., Angiogenesis and lymphangiogenesis in thyroid proliferative lesions: relationship to type and tumour behaviour. Endocr Relat Cancer 13:931-944, 2006.

13.Scarpino, S. D'Alena, FC. Di Napoli, A. Ballarini, F. Prat, M. Ruco, LP., Papillary carcinoma of the thyroid: evidence for a role for hepatocyte growth factor (HGF) in promoting tumour angiogenesis. J Pathol, 199:243-250, 2003.

14.Hsueh, C. Lin, JD. Wu, IC. Chao, TC, Yu JS, Liou MJ, Yeh CJ. Vascular endothelial growth factors and angiopoietins in presentations and prognosis of papillary thyroid carcinoma. J Sirg Oncol, 103:395399, 2011.

15.Holmes, DI. Zachary, I., The vascular endothelial growth factor (VEGF) family: angiogenic factors in health and disease. Genome Biol, 6:209, 2005 doi: 10.1186/gb2005-6-2-209

16.Dailey, ME. Lindsay, S. Skahen, R., Relation of thyroid neoplasms to Hashimoto's disease of the thyroid gland. Arch Surg. 70:291-297, 1955.

17.Konturek, A. Barczyński, M. Wierzchowski, W. Stopa, M. Nowak, W., Coexistence of papillary thyroid cancer with Hashimoto thyroiditis. Langenbecks Arch Surg, 398:389-394, 2013.

18. Sheils, OM. O'Leary, JJ. Uhlmann, V. Lüttich, K. Sweeney, EC., RET/PTC-1 activation in Hashimoto thyroiditis. $J$ Surg Pathol, 8:185-189, 2000.

19.Cyniak-Magierska, A. WojciechowskaDurczyńska, K. Krawczyk-Rusiecka, K. Zygmunt A, Lewiński A. Assessment of RET/PTC1 and RET/PTC3 rearrangements in fine-needle aspiration biopsy specimens collected from patients with Hashimoto's thyroiditis. Thyroid Res, 10:4-5, 2011 